\title{
Publisher Correction: CRISPR gets crunchy
}

Jim Kling

Correction to: Lab Animal https://doi.org/10.1038/s41684-020-00691-x, published online 7 December 2020.

In the version of this article initially published, the first sentence said that the Norwegian Nobel Committee awarded the 2020 Nobel Prize in Chemistry. The sentence should have said that the prize was awarded by the the Royal Swedish Academy of Sciences. The error has been corrected in the HTML and PDF versions of the article.

Published online: 8 April 2021

https://doi.org/10.1038/s41684-021-00757-4

๑ The Author(s), under exclusive licence to Springer Nature America, Inc. 2021

\section{Publisher Correction: Looking into Lyme in the mouse brain}

Ellen Neff

Correction to: Lab Animal https://doi.org/10.1038/s41684-021-00744-9, published online 17 March 2021.

The version of this article initially published contained a stock image of a tick species that does not carry the bacteria that cause Lyme disease. The image and caption have been removed from the HTML and PDF versions of the article.

Published online: 30 April 2021

https://doi.org/10.1038/s41684-021-00775-2

๑ The Author(s), under exclusive licence to Springer Nature America, Inc. 2021 